\title{
Insulin Resistance: A Proinflammatory State Mediated by Lipid-Induced Signaling Dysfunction and Involved in Atherosclerotic Plaque Instability
}

\author{
Fabrizio Montecucco, Sabine Steffens, and François Mach \\ Division of Cardiology, Foundation for Medical Researches, University Hospital, 1211 Geneva, Switzerland \\ Correspondence should be addressed to François Mach, francois.mach@medecine.unige.ch
}

Received 5 February 2008; Accepted 9 June 2008

Recommended by Fulvio D’Acquisto

\begin{abstract}
The dysregulation of the insulin-glucose axis represents the crucial event in insulin resistance syndrome. Insulin resistance increases atherogenesis and atherosclerotic plaque instability by inducing proinflammatory activities on vascular and immune cells. This condition characterizes several diseases, such as type 2 diabetes, impaired glucose tolerance (IGT), impaired fasting glucose (IFG), obesity, hypertension, dyslipidemia, and other endocrinopathies, but also cancer. Recent studies suggest that the pathophysiology of insulin resistance is closely related to interferences with insulin-mediated intracellular signaling on skeletal muscle cells, hepatocytes, and adipocytes. Strong evidence supports the role of free fatty acids (FFAs) in promoting insulin resistance. The FFA-induced activation of protein kinase C (PKC) delta, inhibitor kappaB kinase (IKK), or c-Jun N-terminal kinase (JNK) modulates insulin-triggered intracellular pathway (classically known as PI3-K-dependent). Therefore, reduction of FFA levels represents a selective target for modulating insulin resistance.
\end{abstract}

Copyright ( $) 2008$ Fabrizio Montecucco et al. This is an open access article distributed under the Creative Commons Attribution License, which permits unrestricted use, distribution, and reproduction in any medium, provided the original work is properly cited.

\section{EPIDEMIOLOGY OF INSULIN RESISTANCE}

Historically, the sweetness of urine and other body fluids in diabetic patients suggested that glucose had an important role in the physiopathology of this common disease. Thus, glucose metabolism and the insulin-glucose axis were the leading fields for scientific investigations. To emphasize this concept, diabetes was called "mellitus." Not only hyperglycaemia is crucial for the diagnosis of diabetes and the development of clinical complications [1], but also increasing evidence demonstrated the involvement of insulin in the physiopathology of this disease. In fact, diabetes is a metabolic disease characterized by hyperglycaemia resulting from either defects in insulin secretion or insulin properties, or both. In the present review, we focus on defects of insulin properties, with particular regard to insulin resistance, which can be defined as a state of reduced responsiveness to normal circulating levels of insulin. This condition is a feature of various disorders, such as type 2 diabetes, which may range from predominantly insulin resistance with relative insulin deficiency to a predominatly secretory defect of insulin [1].
Insulin resistance is also implicated in impaired glucose tolerance (IGT) or impaired fasting glucose (IFG), both considered as "prediabetes" by the Expert Committee on the Diagnosis and Classification of Diabetes Mellitus [2-4], as well as in obesity, hypertension, dyslipidaemia (all disorders clustering in the so-called metabolic syndrome) [5], other endocrinopathies [6], but also in different diseases, such as cancer, infections or rheumatic, and autoimmune diseases [7-11]. Therefore, given the association between insulin resistance and different diseases, no epidemiological data are available, specifically focused on insulin resistance syndrome prevalence or incidence. Furthermore, only recently (in 1997) the WHO have accepted obesity as an epidemic public health burden in adults, without evaluating a well-defined method to monitoring the problem in children [12-15]. Finally, still few clinical studies on Asian and African cohorts focused on insulin resistance and related diseases have been published [16-19]. For all these reasons, to better define insulin resistance epidemiology syndrome requires more investigations. Mechanisms of insulin resistance remain also unknown. Insulin resistance was initially recognized as an 
"allergy" to insulin, with the production of antibodies anti-insulin [20, 21]. Further investigations showed that metabolism of both nonesterified fatty acids (NEFA) and free fatty acids (FFAs) was a crucial step in the development of insulin resistance $[22,23]$. On the basis of these new evidences, Shafrir and Raz suggested in 2003 that diabetes should be now called "lipidus" instead of "mellitus" [24]. Given the importance of physiological effects of insulin during atherogenesis [25-27], there is a need to better clarify the complexity of mechanisms underlying insulin resistance.

\section{MECHANISMS OF INSULIN RESISTANCE}

Insulin is an anabolic essential hormone for the maintenance of glucose omeostasis, tissue growth, and development [28]. It is well known that insulin is secreted by the pancreatic $\beta$ cells mainly in response to increased blood levels of glucose and aminoacids after the meals (extrinsic rhythm) [29]. In addition, the concentration of insulin in the blood displays regular variations independently from the food intake [30]. In fact, two rhythms with periods of 5-10 minutes and 60120 minutes have been documented (intrinsic rhythm) [3133]. The extrinsic rhythm was found altered in a lot of diseases including gestational diabetes [34], maturity onset diabetes of the young (MODY) $1[35,36]$, MODY 3 [37], and Chagas' disease [38]. Furthermore, an altered plasma insulin secretory response has been also observed as an effect of aging processes [39]. On the contrary, the intrinsic rhythm has been found altered in various diseases, such as type 2 diabetes (i.e., MODY 2 as well as maternally inherited diabetes and deafness (MIDD)) [40, 41], obesity [42], and hypertension [43]. Several genetic and molecular studies have been performed to investigate the causes of the dysregulated plasma insulin pattern. Although genetic mutations account for a minor role in the large part of insulin resistance, an alteration of insulin signal transduction, which may be due to genetic mutations, could contribute to the impairment of insulin secretory profile and insulin resistance. Thus, mutations of glucokinase phosphorylated glucose, hepatic nuclear factor-4 alpha, hepatic nuclear factor-1 alpha, mitochondrial tRNALeu(UUR), and also insulin receptor genes have been found [35, 37, 44-46]. For instance, a mutation in the insulin receptor gene of the pancreatic $\beta$ cells has been correlated with a defective insulin-mediated intracellular signal transduction [46]. On the other hand, obesity and increased FFA levels mediate insulin resistance by inducing a decreased IRS-1-associated phosphatidylinositol 3-kinase (PI3-K) activity [47]. In line with these findings, it has been shown that insulin resistance was reversed when obese persons lose weight [48]. However, this weight loss did not restore normal insulin pulsatiliy in Type 2 diabetes patients [49]. These data suggest that the defective insulin-mediated intracellular signal transduction is not the only cause responsible for insulin resistance, and that the molecular mechanisms of insulin resistance are not completely understood. We will discuss in the following the potential mechanisms contributing to insulin resistance which are currently under investigation.

\subsection{Defects on insulin signaling}

The insulin receptor is considered to play a critical role in insulin resistance. It is a member of the receptor tyrosine kinase family [50], composed of two $\alpha$-subunits and two $\beta$ subunits linked together by disulphide bonds. Two isoforms of insulin receptors are known, exhibiting different affinity for insulin and distribution within tissues. Although it is tempting to suggest that differences in binding activity could contribute to insulin resistance, experimental evidence for the involvement of receptor isoforms or receptor hybrids remains controversial [29]. Apart from the insulin binding step to its receptor, the receptor intracellular tyrosine kinase domains (capable of intrinsic kinase activity) have been investigated in view of their possible implication in insulin resistance. A variety of scaffolding proteins, including insulin receptor substrate (IRS) proteins, casitas B lineage lymphoma (Cbl), or $\mathrm{Cbl}$ associated protein (CAP), bind to intracellular receptor sites and become phosphorylated [5153]. IRS-1 and -2 are considered the most important proteins in regulation of glucose metabolism [54]. As shown in knockout mouse models, IRS-1 or IRS-2 inactivation causes insulin resistance $[55,56]$. In addition, in vitro experiments showed an increased serine phosphorylation of IRS by tumor necrosis factor-alpha (TNF- $\alpha$ ) or FFA stimulation, thereby causing impaired insulin signal transduction [54, 57]. Finally, a prolonged exposure to insulin (a typical condition in hyperinsulinemic patients) may result in a degradation of IRS protein [58]. All together, these data support IRS-1 and IRS-2 as crucial players in the development of insulin resistance. Furthermore, numerous studies aimed to identify downstream elements of IRS proteins in the insulinmediated signal transduction pathway. As mentioned above, $\mathrm{PI} 3-\mathrm{K}$ is considered the central mediator [59]. Three different isoforms of this kinase have been identified: Ia, PI3-K/Akt, capable of generating phosphatidylinositol 4,5-bisphosphate (PIP2) and phosphatidylinositol 3,4,5-trisphosphate (PIP3); $\mathrm{Ib}, \mathrm{G}$ protein regulated kinase; II, incapable of generating PIP2 and PIP3. As shown in Figure 1(a), activated PI3-K is responsible for the beginning of a complex phosphorylation cascade, involving the phospholipids PIP2, PIP3, the phosphoinositide-dependent kinase 1 (PDK1), the protein kinase $\mathrm{B}(\mathrm{PKB}$, also called Akt), as well as the protein kinase $\mathrm{C}$ (PKC). Akt mediates the effects of insulin on glucose transport (GLUT) [60], glycogen synthesis, protein synthesis, lipogenesis, and suppression of hepatic gluconeogenesis [59]. Once activated, Akt detaches from the plasma membrane and translocates into the nucleus through a still unknown mechanism [61], or activates different substrates, such as glycogen synthase kinase-3 (GSK-3) and transcription factors of the Foxo-family [59]. All these proteins and phospholipids are likely to be implicated in insulin resistance. For instance, a reduced PI3-K activity has been reported in skeletal muscle and adipocytes of patients with insulin resistance [62-64]. In addition, Akt activation has been found reduced in several diseases associated with insulin resistance $[65,66]$. However, Akt involvement in insulin resistance is controversial, since other studies did not show any alteration of Akt activation in insulin resistance 


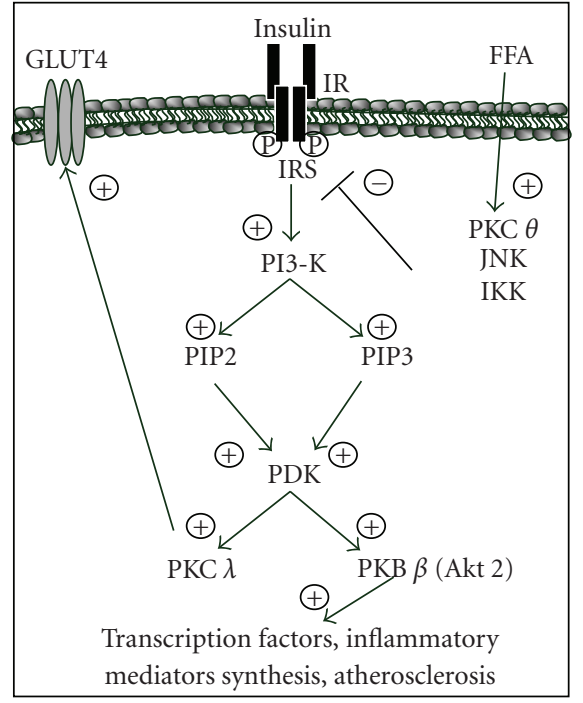

(a) Molecular mechanism involved in insulin resistance

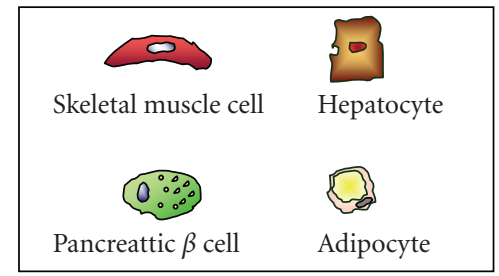

(b) Main cell types involved in the development of insulin resistance

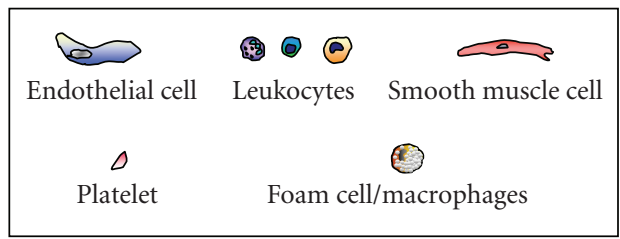

(c) Main cell types activated by hyperinsulinemia in atherosclerotic inflammatory processes

FIGURE 1: Lipid signaling interference generates insulin resistance. (a) Signaling through phosphatidylinositol 3-kinase (PI3-K) is crucial for insulin-mediated glucose transport in hepatocytes and skeletal muscle cells and for inflammatory protein and hormone secretion in adipocytes and pancreatic $\beta$ cells. Free fatty acids (FFAs) induce a defective insulin-mediated signaling mainly through the activation of protein kinase $\mathrm{C}(\mathrm{PKC} \theta)$, inhibitor $\kappa \mathrm{B}$ kinase (IKK) and c-Jun N-terminal kinase (JNK). (b) Main cell types involved in the development of insulin resistance. (c) Main inflammatory cell populations involved in hyperinsulinemia-induced inflammatory states.

associated syndromes $[67,68]$. On the other hand, insulininduced PKC activation has been found altered in type 2 diabetic [69] or obese [70] patients. Therefore, although other studies are needed, all these observations suggest that a reduction of insulin-mediated intracellular signaling is crucial for the establishment of insulin resistance.

Another possible mechanism leading to insulin resistance might be an upregulation of protein-tyrosine phosphatases (PTPases), capable of functioning as negative regulators of the insulin-triggered pathway. Among various proteins, PTP 1B has been shown as a key regulator of insulin signaling [71-73]. Other phosphatases, such as ectonucleotide pyrophosphatase phosphodiesterase 1 (ENPP1, also known as PC-1), SH-2-containing inositol 5' -phosphatase 2 (SHIP2), and phosphatase and tensin homolog deleted on chromosome 10 (PTEN) have been shown to interfere with insulin sensitivity [74-76]. Although further investigations are warranted to very verify these hypotheses, these proteins may represent future potential targets for the treatment of insulin resistance.

\subsection{Glucose metabolism}

Glucose uptake into muscle and fat tissue depends on glucose transporter 4 (GLUT4) expression on the cell membrane. Insulin reduces glycaemia, mainly by inducing the secretion of this molecule by muscle and fat cells [77]. However, GLUT4 polymorphisms or mutations inactivating GLUT4 gene were not associated with insulin resistance [78]. In addition, GLUT4 concentrations in skeletal muscle of insulin resistant patients were not reduced [79]. This suggests that alterations in GLUT4 expression are not a primary cause for the development of insulin resistance. In this context, the correct functioning of insulin intracellular signalization appears essential. In fact, GLUT4 upregulation represents the final event of insulin signaling cascade [80-82]. Among various kinases (Figure 1(a)), Akt $\beta$ has been shown to play an essential role. Recently, in vitro and in vivo studies suggested that $\mathrm{PKB} \beta$ alterations [83] or disruption [84] are responsible for the reduction of insulin-induced glucose uptake. Consistent with these data, recent studies in humans detected a missense mutation in the kinase domain of $\mathrm{PKB} \beta$ (Akt 2) associated with severe insulin resistance [85]. These data suggest that insulin signaling also plays crucial role in the regulation glucose homeostasis.

\subsection{Inflammatory molecules}

Recent evidence suggests that inflammation might be crucial for the development of insulin resistance [86]. Proinflammatory cytokines and acute-phase reactants are positively correlated with insulin resistance in metabolic syndrome patients [87]. Among these soluble mediators, interleukin (IL)-1 and IL-1 receptor antagonist (RA) have been implicated in the development of insulin resistance in humans $[88,89]$ and in rodents [90, 91]. IL-1RA is anaturally occurring cytokine and a member of the IL-1 family whose only function is to prevent a biologic response to IL1 [92]. In humans, the blockade of IL-1 with IL-1 RA improves glycaemia and beta-cell secretory function and reduces markers of systemic inflammation [93]. Accordingly, IL-1 has been shown to induce insulin resistance mainly 
by inhibiting insulin-mediated signaling $[94,95]$. Thus, IL1 has to be considered as an important factor involved in insulin resistance. TNF- $\alpha$ and IL- 6 are also of particular interest, because of their increased expression in adipose tissue and their capacity to induce insulin resistance [96]. Further evidence for the link between TNF- $\alpha$ and insulin resistance was provided by a study using blocking anti-TNF$\alpha$ antibodies in obese rodents or TNF- $\alpha$ knockout obese mice [97]. In these animals, a reduced insulin resistance was obtained by the suppression of TNF- $\alpha$. The possible molecular mechanism of TNF- $\alpha$-induced insulin resistance may involve IRS-1 [98]. Surprisingly, the infusion of antiTNF- $\alpha$ antibody in humans did not affect insulin resistance. Further investigations are needed to better understand these opposite results obtained in human and mice. On the other hand, the role of IL- 6 in insulin resistance is also controversial. IL-6 interferes with the metabolism of both adipose and skeletal muscle tissues [99, 100], but has also a positive effect on skeletal muscle cell insulin sensitivity [101]. In addition, IL-15 has been shown to play a possible role in myocyte-adipocyte crosstalk, but only few studies are published at present to better clarify its role in insulin resistance [102]. Moreover, it is now established that hormones from adipose tissue hormones contribute to insulin resistance. For instance, leptin has been shown to reverse insulin resistance in mice with congenital lipodystrophy [103]. Administration of leptin to patients with lipodystrophy can increase the body fat content and reverse insulin resistance [104]. Resistin, a new adipocyte hormone [105], may be another important link between increased fat mass and insulin resistance [106]. Resistin decreases insulin-dependent glucose transport in vitro and increases fasting blood glucose concentrations and hepatic glucose production in vivo [106-109]. Similarly, the reduction of adiponectin could contribute to insulin resistance. Very recently, adiponectin has been showed as an anti-inflammatory and immunomodulatory molecule $[110,111]$. In humans, adiponectin levels correlate with insulin sensitivity. Mice deficient in adiponectin are insulin resistant [112] and the administration of adiponectine to obese and insulin resistant mice has been shown to improve insulin sensitivity [113-115]. In addition, inflammatory mediators such as the proinflammatory chemokine monocyte chemotactic protein-1 (MCP-1) are believed to play a role in the pathogenesis of insulin resistance. Recent in vitro evidence suggests that MCP-1 induces insulin resistance in both adipocytes and skeletal muscle cells [116]. Finally, retinol-binding protein (RBP)-4 and tissue inhibitors of metalloproteinases (TIMP)-1 were recently described to contribute to insulin resistance in vivo, but the underlying mechanism remains unclear [117-119]. In conclusion, at the present state of knowledge, insulin resistance has to be defined as a complex syndrome involving not only glucose and lipids, but also several proinflammatory molecules.

\subsection{Lipids and insulin resistance}

Lipid abnormalities, such as increased circulating free fatty acids, are frequently associated with insulin resistance [120]. Lipid metabolism induces insulin resistance through a well- known cascade of events. The excessive fat intake causes an increased influx of triglycerides into the blood and an excess of plasma levels of FFAs, which induce insulin resistance, with consequent hyperglycaemia. The increased levels of glucose stimulate pancreatic $\beta$ cells to secrete more and more insulin, generating hyperinsulinemia, which further triggers the elevation of triglycerides and closes the vicious circle [121]. When insulin secretion is not sufficient and elevated glucose levels prevail, diabetes becomes overt. Defective insulin secretion is a result of chronic exposure to elevated levels of fatty acids, which inhibits insulin gene expression by functioning as true toxic agents for pancreatic $\beta$ cells [122]. "Lipotoxicity" depends on the interference with insulin-mediated intracellular signaling in various cell types (Figure 1). In particular, FFAs have been shown to activate PKC $\theta$ (Figure 1(a)), which not only interferes with insulin signaling (by inducing insulin resistance), but also is implicated in promoting proatherogenic mechanisms, such as endothelial dysfunction, growth, migration, and apoptosis of vascular smooth muscle cells, induction of adhesion molecules and oxidized low-density lipoprotein uptake of oxidized low-density lipoprotein by monocytederived macrophages [123]. Furthermore, it was recently shown that FFAs induce insulin resistance in muscle through the activation of inhibitor $\kappa \mathrm{B}$ kinase (IKK) and c-Jun Nterminal kinase (JNK) (Figure 1(a)) [124]. Therefore, FFAs induce insulin resistance in hepatocytes and skeletal muscle cells through the activation of different kinases (Figures 1(a) and 1(b)). Both FFAs from plasma and those released from stored triglycerides activate second messangers, which alter insulin signaling [125]. FFAs are also involved in modulating insulin production by pancreatic $\beta$-cells and cytokine secretion by hepatocytes, adipocyte, muscle cells, and inflammatory cells (Figure 1(c)). This strongly supports FFA as important proatherosclerotic agents.

\section{ROLE OF INSULIN RESISTANCE IN ATHEROSCLEROTIC PLAQUE INSTABILITY}

The development of atherosclerotic plaques is dependent on the interaction of multistep biochemical processes that lead to the plaque formation, maturation, and complication [126]. Plaque instability, rupture, and thrombosis are crucial events in the acute artery occlusion, which causes dramatic ischemic consequences in the heart, brain, and also peripheral tissues. Insulin resistance is considered to be a pivotal event in the increased risk of plaque instability through different pathways [127, 128]. High concentrations of insulin directly increase proinflammatory activities of leukocytes, which are involved in atherosclerotic plaque instability. In particular, insulin directly increases neutrophil and monocyte in vitro migration in response to chemokines secreted in atherosclerotic plaques $[129,130]$. Insulin could also favor atherosclerotic plaque necrosis by accelerating macrophage death [131]. Furthermore, insulin induces in vivo production of matrix metalloproteinase-9 (MMP-9), which is responsible for plaque instability and rupture [132-134]. The pharmacologic or behavioral treatments to reduce insulin resistance have been shown to inhibit 
MMP-9 secretion $[126,135,136]$. On the other hand, insulin could also induce a serious atherothrombotic state, by increasing platelet resistance to antiaggregating agents [137] and production of procoagulatory factors, such as plasminogen activator inhibitor-1 (PAI-1), factor VII, factor XII, fibrinogen, and tissue plasminogen activator [126]. These evidences strongly support an emerging role of insulin in plaque instability and rupture. Further investigations are needed to better clarify the specific roles and the interactions of insulin and lipids on inflammatory cells.

\section{CONCLUSION REMARKS}

In the last years, the standard definition of insulin resistance has been shifted from a traditional "glucocentric" to a new "lipocentric" view [138]. Several soluble mediators are involved in the development of insulin resistance, through generating insulin signaling dysfunction. Among these, FFAs have to be considered as proatherosclerotic agents, capable of interfering with insulin signaling and provoking insulin resistance. New and selective therapies contrasting FFA effects may be promising targets for the treatment of insulin resistance. A possible promising strategy capable of reducing the consequences of excessive lipolysis and reorient FFA flux toward adipose tissue might be represented by peroxisome proliferator-activated receptor (PPAR)- $\alpha$ and $\gamma$ agonists [139]. PPAR- $\gamma$ agonists have been recently shown to regulate trygliceride lipase in adipocytes in vitro and in vivo [140]. Furthermore, PPAR- $\gamma$ has been shown as crucial in the control of differentiation of human monocytes in M2 macrophages, the subset of macrophages resident in atherosclerotic plaques with anti-inflammatory activity [141]. In vivo studies have also demonstrated that PPAR- $\gamma$ agonists treatment in patients with type 2 diabetes mellitus is associated with a reduction in plasma NEFA levels [142145]. However, two recent important clinical studies have shown an increase of acute cardiovascular outcomes induced by treatment with thiazolidinediones (PPAR- $\gamma$ agonists) $[146,147]$. On the other hand, although PPAR- $\alpha$ has been shown to have vascular and metabolic beneficial effects, the activity of PPAR- $\alpha$ agonists on lipid metabolism is still controversial [148, 149]. Therefore, further trials are needed to recommend the use of these pharmacological agents for reducing lipid-mediated insulin resistance.

\section{ACKNOWLEDGMENTS}

This work was supported by grants from the Swiss National Science Foundation to Dr F. Mach (Grant no. 320080-105836) and Dr S. Steffens (Grant no. 310000116324), and Foundation for Medical Research (Geneva). The authors belong to the European Vascular Genomics Network (http://www.evgn.org/) a Network of Excellence supported by the European Community.

\section{REFERENCES}

[1] American Diabetes Association, "Diagnosis and classification of diabetes mellitus," Diabetes Care, vol. 30, supplement 1, pp. S42-S47, 2007.
[2] J. R. Gavin III, K. G. M. M. Alberti, M. B. Davidson, et al., "Report of the Expert Committee on the Diagnosis and Classification of Diabetes Mellitus," Diabetes Care, vol. 20, no. 7, pp. 1183-1197, 1997.

[3] The Expert Committee on the Diagnosis and Classification of Diabetes Mellitus, "Follow-up report on the diagnosis of diabetes mellitus," Diabetes Care, vol. 26, no. 11, pp. 31603167, 2003.

[4] D. J. Rader, "Effect of insulin resistance, dyslipidemia, and intra-abdominal adiposity on the development of cardiovascular disease and diabetes mellitus," The American Journal of Medicine, vol. 120, no. 3, supplement 1, pp. S12-S18, 2007.

[5] R. H. Eckel, S. M. Grundy, and P. Z. Zimmet, "The metabolic syndrome," The Lancet, vol. 365, no. 9468, pp. 1415-1428, 2005.

[6] S. Caprio, D. Boulware, and V. Tamborlane, "Growth hormone and insulin interactions," Hormone Research, vol. 38, supplement 2, pp. 47-49, 1992.

[7] E. Giovannucci, "Metabolic syndrome, hyperinsulinemia, and colon cancer: a review," The American Journal of Clinical Nutrition, vol. 86, no. 3, pp. 836S-842S, 2007.

[8] P. J. Goodwin, M. Ennis, M. Bahl, et al., "High insulin levels in newly diagnosed breast cancer patients reflect underlying insulin resistance and are associated with components of the insulin resistance syndrome," Breast Cancer Research and Treatment. In press.

[9] D. S. Bell, "Inflammation, insulin resistance, infection, diabetes, and atherosclerosis," Endocrine Practice, vol. 6, no. 3, pp. 272-276, 2000.

[10] B. Seriolo, C. Ferrone, and M. Cutolo, "Longterm antitumor necrosis factor- $\alpha$ treatment in patients with refractory rheumatoid arthritis: relationship between insulin resistance and disease activity," The Journal of Rheumatology, vol. 35, no. 2, pp. 355-357, 2008.

[11] A. Oguz, E. G. Dogan, M. Uzunlulu, and F. M. Oguz, "Insulin resistance and adiponectin levels in Behçet's syndrome," Clinical and Experimental Rheumatology, vol. 25, no. 4, supplement 45, pp. S118-S119, 2007.

[12] P. A. Sarafidis and G. L. Bakris, "Insulin resistance, hyperinsulinemia, and hypertension: an epidemiologic approach," Journal of the CardioMetabolic Syndrome, vol. 1, no. 5, pp. 334-344, 2006.

[13] G. M. Reaven, "Insulin resistance, the insulin resistance syndrome, and cardiovascular disease," Panminerva Medica, vol. 47, no. 4, pp. 201-210, 2005.

[14] W. P. T. James, "The epidemiology of obesity: the size of the problem," Journal of Internal Medicine, vol. 263, no. 4, pp. 336-352, 2008.

[15] M. A. Sabin and J. P. Shield, "Childhood obesity," Frontiers of Hormone Research, vol. 36, pp. 85-96, 2008.

[16] E. A. Enas, V. Mohan, M. Deepa, S. Farooq, S. Pazhoor, and H. Chennikkara, "The metabolic syndrome and dyslipidemia among Asian Indians: a population with high rates of diabetes and premature coronary artery disease," Journal of the CardioMetabolic Syndrome, vol. 2, no. 4, pp. 267-275, 2007.

[17] D. P. Schuster, T. Gaillard, and K. Osei, “The cardiometabolic syndrome in persons of the African diaspora: challenges and opportunities," Journal of the CardioMetabolic Syndrome, vol. 2, no. 4, pp. 260-266, 2007.

[18] K. C. Hoang, T. V. Le, and N. D. Wong, "The metabolic syndrome in East Asians," Journal of the CardioMetabolic Syndrome, vol. 2, no. 4, pp. 276-282, 2007. 
[19] M. Reimann, A. E. Schutte, and P. E. H. Schwarz, "Insulin resistance-the role of ethnicity: evidence from Caucasian and African cohorts," Hormone and Metabolic Research, vol. 39, no. 12, pp. 853-857, 2007.

[20] F. C. Lowell, "Immunologic studies in insulin resistance I. Report of a case exhibiting variations in resistance and allergy to insulin," The Journal for Clinical Investigation, vol. 23, no. 2, pp. 225-231, 1944.

[21] W. B. Sherman, "A case of coexisting insulin allergy and insulin resistance," Journal of Allergy, vol. 21, no. 1, pp. 4954, 1950.

[22] M. Krebs, M. Krssak, P. Nowotny, et al., "Free fatty acids inhibit the glucose-stimulated increase of intramuscular glucose-6-phosphate concentration in humans," The Journal of Clinical Endocrinology \& Metabolism, vol. 86, no. 5, pp. 2153-2160, 2001.

[23] P. J. Randle, P. B. Garland, C. N. Hales, and E. A. Newsholme, "The glucose fatty acids cycle: its role in insulin sensitivity and the metabolic disturbances of diabetes mellitus," The Lancet, vol. 281, no. 7285, pp. 785-789, 1963.

[24] E. Shafrir and I. Raz, "Diabetes: mellitus or lipidus?" Diabetologia, vol. 46, no. 3, pp. 433-440, 2003.

[25] J. D. Cameron and J. K. Cruickshank, "Glucose, insulin, diabetes and mechanisms of arterial dysfunction," Clinical and Experimental Pharmacology and Physiology, vol. 34, no. 7, pp. 677-682, 2007.

[26] C. Lara-Castro, Y. Fu, B. H. Chung, and W. T. Garvey, "Adiponectin and the metabolic syndrome: mechanisms mediating risk for metabolic and cardiovascular disease," Current Opinion in Lipidology, vol. 18, no. 3, pp. 263-270, 2007.

[27] S. R. Kashyap and R. A. DeFronzo, "The insulin resistance syndrome: physiological considerations," Diabetes \& Vascular Disease Research, vol. 4, no. 1, pp. 13-19, 2007.

[28] R. J. Kones and J. H. Phillips, "Insulin: fundamental mechanism of action and the heart," Cardiology, vol. 60, no. 5, pp. 280-303, 1975.

[29] G. Sesti, "Pathophysiology of insulin resistance," Best Practice \& Research in Clinical Endocrinology \& Metabolism, vol. 20, no. 4, pp. 665-679, 2006.

[30] P. Bergsten, "Pathophysiology of impaired pulsatile insulin release," Diabetes/Metabolism Research and Reviews, vol. 16, no. 3, pp. 179-191, 2000.

[31] C. J. Goodner, B. C. Walike, D. J. Koerker, et al., "Insulin, glucagon, and glucose exhibit synchronous, sustained oscillations in fasting monkeys," Science, vol. 195, no. 4274, pp. 177-179, 1977.

[32] C. Simon, G. Brandenberger, and M. Follenius, "Ultradian oscillations of plasma glucose, insulin, and C-peptide in man during continuous enteral nutrition," The Journal of Clinical Endocrinology \& Metabolism, vol. 64, no. 4, pp. 669-674, 1987.

[33] K. S. Polonsky, J. Sturis, and E. Van Cauter, "Temporal profiles and clinical significance of pulsatile insulin secretion," Hormone Research, vol. 49, no. 3-4, pp. 178-184, 1998.

[34] E. A. Ryan, S. Imes, D. Liu, et al., "Defects in insulin secretion and action in women with a history of gestational diabetes," Diabetes, vol. 44, no. 5, pp. 506-512, 1995.

[35] W. H. Herman, S. S. Fajans, M. J. Smith, K. S. Polonsky, G. I. Bell, and J. B. Halter, "Diminished insulin and glucagon secretory responses to arginine in nondiabetic subjects with a mutation in the hepatocyte nuclear factor- $4 \alpha /$ MODY 1 gene," Diabetes, vol. 46, no. 11, pp. 1749-1754, 1997.
[36] E. H. Hani, L. Suaud, P. Boutin, et al., "A missense mutation in hepatocyte nuclear factor- $4 \alpha$, resulting in a reduced transactivation activity, in human late-onset noninsulin-dependent diabetes mellitus," The Journal of Clinical Investigation, vol. 101, no. 3, pp. 521-526, 1998.

[37] J.-F. Surmely, E. Guenat, J. Philippe, et al., "Glucose utilization and production in patients with maturity-onset diabetes of the young caused by a mutation of the hepatocyte nuclear factor- $1 \alpha$ gene," Diabetes, vol. 47, no. 9, pp. 1459-1463, 1998.

[38] R. G. Long, R. H. Albuquerque, A. Prata, et al., "Response of plasma pancreatic and gastrointestinal hormones and growth hormone to oral and intravenous glucose and insulin hypoglycaemia in Chagas's disease," Gut, vol. 21, no. 9, pp. 772-777, 1980.

[39] L. F. Samos and B. A. Roos, "Diabetes mellitus in older persons," Medical Clinics of North America, vol. 82, no. 4, pp. 791-803, 1998.

[40] D. A. Lang, D. R. Matthews, M. Burnett, and R. C. Turner, "Brief, irregular oscillations of basal plasma insulin and glucose concentrations in diabetic man," Diabetes, vol. 30, no. 5, pp. 435-439, 1981.

[41] S. O'Rahilly, R. C. Turner, and D. R. Matthews, "Impaired pulsatile secretion of insulin in relatives of patients with non-insulin-dependent diabetes," The New England Journal of Medicine, vol. 318, no. 19, pp. 1225-1230, 1988.

[42] E. Van Cauter, K. S. Polonsky, J. D. Blackman, et al., "Abnormal temporal patterns of glucose tolerance in obesity: relationship to sleep-related growth hormone secretion and circadian cortisol rhythmicity," The Journal of Clinical Endocrinology \& Metabolism, vol. 79, no. 6, pp. 1797-1805, 1994.

[43] U. B. Andersen, H. Dige-Petersen, E. K. Frandsen, H. Ibsen, and A. Vølund, "Basal insulin-level oscillations in normotensive individuals with genetic predisposition to essential hypertension exhibit an irregular pattern," Journal of Hypertension, vol. 15, no. 10, pp. 1167-1173, 1997.

[44] J. M. W. van den Ouweland, P. Maechler, C. B. Wollheim, G. Attardi, and J. A. Maassen, "Functional and morphological abnormalities of mitochondria harbouring the tRNA(Leu(UUR)) mutation in mitochondrial DNA derived from patients with maternally inherited diabetes and deafness (MIDD) and progressive kidney disease," Diabetologia, vol. 42, no. 4, pp. 485-492, 1999.

[45] H. Sakura, S. J. H. Ashcroft, Y. Terauchi, T. Kadowaki, and F. M. Ashcroft, "Glucose modulation of ATP-sensitive K-currents in wild-type, homozygous and heterozygous glucokinase knock-out mice," Diabetologia, vol. 41, no. 6, pp. 654-659, 1998.

[46] R. N. Kulkarni, J. C. Brüning, J. N. Winnay, C. Postic, M. A. Magnuson, and C. R. Kahn, "Tissue-specific knockout of the insulin receptor in pancreatic $\beta$ cells creates an insulin secretory defect similar to that in type 2 diabetes," Cell, vol. 96, no. 3, pp. 329-339, 1999.

[47] A. Dresner, D. Laurent, M. Marcucci, et al., "Effects of free fatty acids on glucose transport and IRS-1-associated phosphatidylinositol 3-kinase activity," The Journal of Clinical Investigation, vol. 103, no. 2, pp. 253-259, 1999.

[48] D. R. Matthews, "Oscillatory insulin secretion: a variable phenotypic marker," Diabetic Medicine, vol. 13, no. 9, supplement 6, pp. S53-S58, 1996.

[49] B. Gumbiner, E. Van Cauter, W. F. Beltz, et al., "Abnormalities of insulin pulsatility and glucose oscillations during meals in obese noninsulin-dependent diabetic patients: effects of 
weight reduction," The Journal of Clinical Endocrinology \& Metabolism, vol. 81, no. 6, pp. 2061-2068, 1996.

[50] A. Ullrich, J. R. Bell, E. Y. Chen, et al., "Human insulin receptor and its relationship to the tyrosine kinase family of oncogenes," Nature, vol. 313, no. 6005, pp. 756-761, 1985.

[51] C. A. Baumann, V. Ribon, M. Kanzaki, et al., "CAP defines a second signalling pathway required for insulin-stimulated glucose transport," Nature, vol. 407, no. 6801, pp. 202-207, 2000.

[52] T. Noguchi, T. Matozaki, K. Inagaki, et al., "Tyrosine phosphorylation of p62 $2^{\text {Dok }}$ induced by cell adhesion and insulin: possible role in cell migration," The EMBO Journal, vol. 18, no. 7, pp. 1748-1760, 1999.

[53] T. Pawson and J. D. Scott, "Signaling through scaffold, anchoring, and adaptor proteins," Science, vol. 278, no. 5346, pp. 2075-2080, 1997.

[54] M. F. White, "IRS proteins and the common path to diabetes," American Journal of Physiology, vol. 283, no. 3, pp. E413-E422, 2002.

[55] J. P. Whitehead, P. Humphreys, A. Krook, et al., "Molecular scanning of the insulin receptor substrate 1 gene in subjects with severe insulin resistance: detection and functional analysis of a naturally occurring mutation in a YMXM motif," Diabetes, vol. 47, no. 5, pp. 837-839, 1998.

[56] S. F. Previs, D. J. Withers, J.-M. Ren, M. F. White, and G. I. Shulman, "Contrasting effects of IRS-1 versus IRS-2 gene disruption on carbohydrate and lipid metabolism in vivo," Journal of Biological Chemistry, vol. 275, no. 50, pp. 38990 38994, 2000.

[57] P. Gual, Y. Le Marchand-Brustel, and J. F. Tanti, "Positive and negative regulation of glucose uptake by hyperosmotic stress," Diabetes \& Metabolism, vol. 29, no. 6, pp. 566-575, 2003.

[58] L. Rui, T. L. Fisher, J. Thomas, and M. F. White, "Regulation of insulin/insulin-like growth factor-1 signaling by proteasome-mediated degradation of insulin receptor substrate-2," Journal of Biological Chemistry, vol. 276, no. 43, pp. 40362-40367, 2001.

[59] S. Schinner, W. A. Scherbaum, S. R. Bornstein, and A. Barthel, "Molecular mechanisms of insulin resistance," Diabetic Medicine, vol. 22, no. 6, pp. 674-682, 2005.

[60] D. R. Alessi and P. Cohen, "Mechanism of activation and function of protein kinase B," Current Opinion in Genetics \& Development, vol. 8, no. 1, pp. 55-62, 1998.

[61] R. Meier, D. R. Alessi, P. Cron, M. Andjelković, and B. A. Hemmings, "Mitogenic activation, phosphorylation, and nuclear translocation of protein kinase B $\beta$," Journal of Biological Chemistry, vol. 272, no. 48, pp. 30491-30497, 1997.

[62] J. T. Brozinick Jr., B. R. Roberts, and G. L. Dohm, "Defective signaling through Akt-2 and -3 but not Akt-1 in insulinresistant human skeletal muscle: potential role in insulin resistance," Diabetes, vol. 52, no. 4, pp. 935-941, 2003.

[63] M. Björnholm, Y. Kawano, M. Lehtihet, and J. R. Zierath, "Insulin receptor substrate-1 phosphorylation and phosphatidylinositol 3-kinase activity in skeletal muscle from NIDDM subjects after in vivo insulin stimulation," Diabetes, vol. 46, no. 3, pp. 524-527, 1997.

[64] U. Smith, M. Axelsen, E. Carvalho, B. Eliasson, P.-A. Jansson, and C. Wesslau, "Insulin signaling and action in fat cells: associations with insulin resistance and type 2 diabetes," Annals of the New York Academy of Sciences, vol. 892, no. 1, pp. 119-126, 1999.

[65] Y.-B. Kim, S. E. Nikoulina, T. P. Ciaraldi, R. R. Henry, and B. B. Kahn, "Normal insulin-dependent activation of
Akt/protein kinase B, with diminished activation of phosphoinositide 3-kinase, in muscle in type 2 diabetes," The Journal of Clinical Investigation, vol. 104, no. 6, pp. 733-741, 1999.

[66] A. Krook, R. A. Roth, X. J. Jiang, J. R. Zierath, and H. Wallberg-Henriksson, "Insulin-stimulated Akt kinase activity is reduced in skeletal muscle from NIDDM subjects," Diabetes, vol. 47, no. 8, pp. 1281-1286, 1998.

[67] A. Krook, M. Björnholm, D. Galuska, et al., "Characterization of signal transduction and glucose transport in skeletal muscle from type 2 diabetic patients," Diabetes, vol. 49 , no. 2 , pp. 284-292, 2000.

[68] M. Beeson, M. P. Sajan, M. Dizon, et al., "Activation of protein kinase $\mathrm{C}-\zeta$ by insulin and phosphatidylinositol$3,4,5-\left(\mathrm{PO}_{4}\right)_{3}$ is defective in muscle in type 2 diabetes and impaired glucose tolerance: amelioration by rosiglitazone and exercise," Diabetes, vol. 52, no. 8, pp. 1926-1934, 2003.

[69] Y.-B. Kim, K. Kotani, T. P. Ciaraldi, R. R. Henry, and B. B. Kahn, "Insulin-stimulated protein kinase $\mathrm{C} \lambda / \zeta$ activity is reduced in skeletal muscle of humans with obesity and type 2 diabetes: reversal with weight reduction," Diabetes, vol. 52, no. 8, pp. 1935-1942, 2003.

[70] M. P. Sajan, M. L. Standaert, A. Miura, et al., "Impaired activation of protein kinase $\mathrm{C}-\zeta$ by insulin and phosphatidylinositol-3,4,5-( $\left.\mathrm{PO}_{4}\right)_{3}$ in cultured preadipocytederived adipocytes and myotubes of obese subjects," The Journal of Clinical Endocrinology \& Metabolism, vol. 89, no. 8, pp. 3994-3998, 2004.

[71] M. Elchebly, P. Payette, E. Michaliszyn, et al., "Increased insulin sensitivity and obesity resistance in mice lacking the protein tyrosine phosphatase-1B gene," Science, vol. 283, no. 5407, pp. 1544-1548, 1999.

[72] B. A. Zinker, C. M. Rondinone, J. M. Trevillyan, et al., "PTP1B antisense oligonucleotide lowers PTP1B protein, normalizes blood glucose, and improves insulin sensitivity in diabetic mice," Proceedings of the National Academy of Sciences of the United States of America, vol. 99, no. 17, pp. 11357-11362, 2002.

[73] F. Ahmad, R. V. Considine, T. L. Bauer, J. P. Ohannesian, C. C. Marco, and B. J. Goldstein, "Improved sensitivity to insulin in obese subjects following weight loss is accompanied by reduced protein-tyrosine phosphatases in adipose tissue," Metabolism, vol. 46, no. 10, pp. 1140-1145, 1997.

[74] J. F. Youngren, B. A. Maddux, S. Sasson, et al., "Skeletal muscle content of membrane glycoprotein PC-1 in obesity. Relationship to muscle glucose transport," Diabetes, vol. 45, no. 10, pp. 1324-1328, 1996.

[75] S. Clément, U. Krause, F. Desmedt, et al., "The lipid phosphatase SHIP2 controls insulin sensitivity," Nature, vol. 409, no. 6816, pp. 92-97, 2001, erratum in Nature, vol. 431, no. 7010, p. 878, 2004.

[76] M. Butler, R. A. McKay, I. J. Popoff, et al., "Specific inhibition of PTEN expression reverses hyperglycemia in diabetic mice," Diabetes, vol. 51, no. 4, pp. 1028-1034, 2002.

[77] J. R. Zierath, L. He, A. Gumà, E. Odegaard Wahlström, A. Klip, and H. Wallberg-Henriksson, "Insulin action on glucose transport and plasma membrane GLUT4 content in skeletal muscle from patients with NIDDM," Diabetologia, vol. 39, no. 10, pp. 1180-1189, 1996.

[78] J. B. Buse, K. Yasuda, T. P. Lay, et al., "Human GLUT4/ muscle-fat glucose-transporter gene: characterization and genetic variation," Diabetes, vol. 41, no. 11, pp. 1436-1445, 1992. 
[79] P. R. Shepherd and B. B. Kahn, "Glucose transporters and insulin action: implications for insulin resistance and diabetes mellitus," The New England Journal of Medicine, vol. 341, no. 4, pp. 248-257, 1999.

[80] B. Cheatham, C. J. Vlahos, L. Cheatham, L. Wang, J. Blenis, and C. R. Kahn, "Phosphatidylinositol 3-kinase activation is required for insulin stimulation of pp70 S6 kinase, DNA synthesis, and glucose transporter translocation," Molecular and Cellular Biology, vol. 14, no. 7, pp. 4902-4911, 1994.

[81] Q. Wang, R. Somwar, P. J. Bilan, et al., "Protein kinase B/Akt participates in GLUT4 translocation by insulin in L6 myoblasts," Molecular and Cellular Biology, vol. 19, no. 6, pp. 4008-4018, 1999.

[82] G. Bandyopadhyay, M. L. Standaert, M. P. Sajan, et al., "Dependence of insulin-stimulated glucose transporter 4 translocation on 3-phosphoinositide-dependent protein kinase- 1 and its target threonine-410 in the activation loop of protein kinase C- $\zeta$," Molecular Endocrinology, vol. 13, no. 10, pp. 1766-1772, 1999.

[83] J. T. Brozinick Jr., B. R. Roberts, and G. L. Dohm, "Defective signaling through Akt-2 and -3 but not Akt-1 in insulinresistant human skeletal muscle: potential role in insulin resistance," Diabetes, vol. 52, no. 4, pp. 935-941, 2003.

[84] H. Cho, J. Mu, J. K. Kim, et al., "Insulin resistance and a diabetes mellitus-like syndrome in mice lacking the protein kinase Akt2 (PKB $\beta)$," Science, vol. 292, no. 5522, pp. 1728 $1731,2001$.

[85] S. George, J. J. Rochford, C. Wolfrum, et al., "A family with severe insulin resistance and diabetes due to a mutation in AKT2," Science, vol. 304, no. 5675, pp. 1325-1328, 2004.

[86] J. C. Pickup, "Inflammation and activated innate immunity in the pathogenesis of type 2 diabetes," Diabetes Care, vol. 27, no. 3, pp. 813-823, 2004.

[87] G. S. Hotamisligil, "Inflammatory pathways and insulin action," International Journal of Obesity, vol. 27, supplement 3, pp. S53-S55, 2003.

[88] S. Perrier, F. Darakhshan, and E. Hajduch, "IL-1 receptor antagonist in metabolic diseases: Dr Jekyll or Mr Hyde?" FEBS Letters, vol. 580, no. 27, pp. 6289-6294, 2006.

[89] J. Jager, T. Grémeaux, M. Cormont, Y. Le Marchand-Brustel, and J.-F. Tanti, "Interleukin- $1 \beta$-induced insulin resistance in adipocytes through down-regulation of insulin receptor substrate-1 expression," Endocrinology, vol. 148, no. 1, pp. 241-251, 2007.

[90] E. Somm, P. Cettour-Rose, C. Asensio, et al., "Interleukin-1 receptor antagonist is upregulated during diet-induced obesity and regulates insulin sensitivity in rodents," Diabetologia, vol. 49, no. 2, pp. 387-393, 2006.

[91] C. Lagathu, L. Yvan-Charvet, J.-P. Bastard, et al., "Long-term treatment with interleukin- $1 \beta$ induces insulin resistance in murine and human adipocytes," Diabetologia, vol. 49, no. 9, pp. 2162-2173, 2006.

[92] C. A. Dinarello, "The role of the interleukin-1-receptor antagonist in blocking inflammation mediated by interleukin-1," The New England Journal of Medicine, vol. 343, no. 10, pp. 732-734, 2000.

[93] C. M. Larsen, M. Faulenbach, A. Vaag, et al., "Interleukin1-receptor antagonist in type 2 diabetes mellitus," The New England Journal of Medicine, vol. 356, no. 15, pp. 1517-1526, 2007.

[94] J. He, I. Usui, K. Ishizuka, et al., "Interleukin-1 $\alpha$ inhibits insulin signaling with phosphorylating insulin receptor substrate-1 on serine residues in 3T3-L1 adipocytes," Molecular Endocrinology, vol. 20, no. 1, pp. 114-124, 2006.
[95] J.-A. Kim, D. C. Yeh, M. Ver, et al., "Phosphorylation of $\mathrm{Ser}^{24}$ in the pleckstrin homology domain of insulin receptor substrate-1 by Mouse Pelle-like kinase/interleukin-1 receptor-associated kinase: cross-talk between inflammatory signaling and insulin signaling that may contribute to insulin resistance," Journal of Biological Chemistry, vol. 280, no. 24, pp. 23173-23183, 2005.

[96] G. S. Hotamisligil, N. S. Shargill, and B. M. Spiegelman, "Adipose expression of tumor necrosis factor- $\alpha$ : direct role in obesity-linked insulin resistance," Science, vol. 259, no. 5091, pp. 87-91, 1993.

[97] K. T. Uysal, S. M. Wiesbrock, M. W. Marino, and G. S. Hotamisligil, "Protection from obesity-induced insulin resistance in mice lacking TNF- $\alpha$ function," Nature, vol. 389, no. 6651, pp. 610-614, 1997.

[98] H. Kanety, R. Feinstein, M. Z. Papa, R. Hemi, and A. Karasik, "Tumor necrosis factor $\alpha$-induced phosphorylation of insulin receptor substrate-1 (IRS-1). Possible mechanism for suppression of insulin-stimulated tyrosine phosphorylation of IRS-1," Journal of Biological Chemistry, vol. 270, no. 40, pp. 23780-23784, 1995.

[99] A. Steensberg, C. Keller, R. L. Starkie, T. Osada, M. A. Febbraio, and B. K. Pedersen, "IL-6 and TNF- $\alpha$ expression in, and release from, contracting human skeletal muscle," American Journal of Physiology, vol. 283, no. 6, pp. E1272E1278, 2002.

[100] G. van Hall, A. Steensberg, M. Sacchetti, et al., "Interleukin-6 stimulates lipolysis and fat oxidation in humans," The Journal of Clinical Endocrinology \& Metabolism, vol. 88, no. 7, pp. 3005-3010, 2003.

[101] C. Weigert, A. M. Hennige, K. Brodbeck, H. U. Häring, and E. D. Schleicher, "Interleukin-6 acts as insulin sensitizer on glycogen synthesis in human skeletal muscle cells by phosphorylation of $\mathrm{Ser}^{473}$ of Akt," American Journal of Physiology, vol. 289, no. 2, pp. E251-E257, 2005.

[102] L. S. Quinn, L. Strait-Bodey, B. G. Anderson, J. M. Argilés, and P. J. Havel, "Interleukin-15 stimulates adiponectin secretion by 3T3-L1 adipocytes: evidence for a skeletal muscle-tofat signaling pathway," Cell Biology International, vol. 29, no. 6, pp. 449-457, 2005.

[103] I. Shimomura, R. E. Hammer, S. Ikemoto, M. S. Brown, and J. L. Goldstein, "Leptin reverses insulin resistance and diabetes mellitus in mice with congenital lipodystrophy," Nature, vol. 401, no. 6748, pp. 73-76, 1999.

[104] E. A. Oral, V. Simha, E. Ruiz, et al., "Leptin-replacement therapy for lipodystrophy," The New England Journal of Medicine, vol. 346, no. 8, pp. 570-578, 2002.

[105] C. M. Steppan, S. T. Bailey, S. Bhat, et al., "The hormone resistin links obesity to diabetes," Nature, vol. 409, no. 6818, pp. 307-312, 2001.

[106] A. R. Shuldiner, R. Yang, and D.-W. Gong, "Resistin, obesity, and insulin resistance- the emerging role of the adipocyte as an endocrine organ," The New England Journal of Medicine, vol. 345, no. 18, pp. 1345-1346, 2001.

[107] B. Moon, J. J.-M. Kwan, N. Duddy, G. Sweeney, and N. Begum, "Resistin inhibits glucose uptake in L6 cells independently of changes in insulin signaling and GLUT4 translocation," American Journal of Physiology, vol. 285, no. 1, pp. E106-E115, 2003.

[108] M. Pravenec, L. Kazdová, V. Landa, et al., “Transgenic and recombinant resistin impair skeletal muscle glucose metabolism in the spontaneously hypertensive rat," Journal of Biological Chemistry, vol. 278, no. 46, pp. 45209-45215, 2003. 
[109] M. W. Rajala, S. Obici, P. E. Scherer, and L. Rossetti, "Adipose-derived resistin and gut-derived resistin-like molecule- $\beta$ selectively impair insulin action on glucose production," The Journal of Clinical Investigation, vol. 111, no. 2, pp. 225-230, 2003.

[110] Y. Okamoto, E. J. Folco, M. Minami, et al., "Adiponectin inhibits the production of CXC receptor 3 chemokine ligands in macrophages and reduces T-lymphocyte recruitment in atherogenesis," Circulation Research, vol. 102, no. 2, pp. 218 225, 2008.

[111] S. Steffens and F. Mach, "Adiponectin and adaptive immunity: linking the bridge from obesity to atherogenesis," Circulation Research, vol. 102, no. 2, pp. 140-142, 2008.

[112] N. Kubota, Y. Terauchi, T. Yamauchi, et al., "Disruption of adiponectin causes insulin resistance and neointimal formation," Journal of Biological Chemistry, vol. 277, no. 29, pp. 25863-25866, 2002.

[113] N. Maeda, I. Shimomura, K. Kishida, et al., "Diet-induced insulin resistance in mice lacking adiponectin/ACRP30," Nature Medicine, vol. 8, no. 7, pp. 731-737, 2002.

[114] A. H. Berg, T. P. Combs, X. Du, M. Brownlee, and P. E. Scherer, "The adipocyte-secreted protein ACRP30 enhances hepatic insulin action," Nature Medicine, vol. 7, no. 8, pp. 947-953, 2001.

[115] T. Yamauchi, J. Kamon, H. Waki, et al., "The fat-derived hormone adiponectin reverses insulin resistance associated with both lipoatrophy and obesity," Nature Medicine, vol. 7, no. 8, pp. 941-946, 2001.

[116] H. Sell and J. Eckel, "Monocyte chemotactic protein-1 and its role in insulin resistance," Current Opinion in Lipidology, vol. 18, no. 3, pp. 258-262, 2007.

[117] Q. Yang, T. E. Graham, N. Mody, et al., "Serum retinol binding protein 4 contributes to insulin resistance in obesity and type 2 diabetes," Nature, vol. 436, no. 7049, pp. 356-362, 2005.

[118] T. E. Graham, Q. Yang, M. Blüher, et al., "Retinol-binding protein 4 and insulin resistance in lean, obese, and diabetic subjects," The New England Journal of Medicine, vol. 354, no. 24, pp. 2552-2563, 2006.

[119] S. Kralisch, J. Klein, U. Lossner, et al., "Proinflammatory adipocytokines induce TIMP-1 expression in 3T3-L1 adipocytes," FEBS Letters, vol. 579, no. 28, pp. 6417-6422, 2005.

[120] W. L. Holland, T. A. Knotts, J. A. Chavez, L.-P. Wang, K. L. Hoehn, and S. A. Summers, "Lipid mediators of insulin resistance," Nutrition Reviews, vol. 65, supplement 1, pp. 3946, 2007.

[121] E. W. Kraegen, G. J. Cooney, J. Ye, and A. L. Thompson, "Triglycerides, fatty acids and insulin resistancehyperinsulinemia," Experimental and Clinical Endocrinology and Diabetes, vol. 109, no. 4, pp. 516-526, 2001.

[122] V. Poitout, D. Hagman, R. Stein, I. Artner, R. P. Robertson, and J. S. Harmon, "Regulation of the insulin gene by glucose and fatty acids," Journal of Nutrition, vol. 136, no. 4, pp. 873876, 2006.

[123] C. Rask-Madsen and G. L. King, "Proatherosclerotic mechanisms involving protein kinase $\mathrm{C}$ in diabetes and insulin resistance," Arteriosclerosis, Thrombosis, and Vascular Biology, vol. 25, no. 3, pp. 487-496, 2005.

[124] Z. Gao, X. Zhang, A. Zuberi, et al., "Inhibition of insulin sensitivity by free fatty acids requires activation of multiple serine kinases in 3T3-L1 adipocytes," Molecular Endocrinology, vol. 18, no. 8, pp. 2024-2034, 2004.
[125] P. Kovacs and M. Stumvoll, "Fatty acids and insulin resistance in muscle and liver," Best Practice \& Research in Clinical Endocrinology \& Metabolism, vol. 19, no. 4, pp. 625-635, 2005.

[126] P. J. Grant, "The genetics of atherothrombotic disorders: a clinician's view," Journal of Thrombosis and Haemostasis, vol. 1, no. 7, pp. 1381-1390, 2003.

[127] J. Amar, L. Perez, R. Burcelin, and B. Chamontin, "Arteries, inflammation and insulin resistance," Journal of Hypertension, vol. 24, supplement 5, pp. S18-S20, 2006.

[128] P. Theuma and V. A. Fonseca, "Inflammation, insulin resistance, and atherosclerosis," Metabolic Syndrome and Related Disorders, vol. 2, no. 2, pp. 105-113, 2004.

[129] F. Montecucco, G. Bianchi, M. Bertolotto, G. Viviani, F. Dallegri, and L. Ottonello, "Insulin primes human neutrophils for CCL3-induced migration: crucial role for JNK 1/2," Annals of the New York Academy of Sciences, vol. 1090, pp. 399-407, 2006.

[130] K. Kappert, H. Meyborg, M. Clemenz, et al., "Insulin facilitates monocyte migration: a possible link to tissue inflammation in insulin-resistance," Biochemical and Biophysical Research Communications, vol. 365, no. 3, pp. 503508, 2008.

[131] I. Tabas, T. Seimon, J. Arellano, et al., "The impact of insulin resistance on macrophage death pathways in advanced atherosclerosis," Novartis Foundation Symposium, vol. 286, pp. 99-109, 2007.

[132] C. K. Roberts, D. Won, S. Pruthi, et al., "Effect of a shortterm diet and exercise intervention on oxidative stress, inflammation, MMP-9, and monocyte chemotactic activity in men with metabolic syndrome factors," Journal of Applied Physiology, vol. 100, no. 5, pp. 1657-1665, 2006.

[133] B. Głowińska-Olszewska and M. Urban, "Elevated matrix metalloproteinase 9 and tissue inhibitor of metalloproteinase 1 in obese children and adolescents," Metabolism, vol. 56, no. 6, pp. 799-805, 2007.

[134] G. Boden, W. Song, L. Pashko, and K. Kresge, "In vivo effects of insulin and free fatty acids on matrix metalloproteinases in rat aorta," Diabetes, vol. 57, no. 2, pp. 476-483, 2008.

[135] A. Ceriello, "Thiazolidinediones as anti-inflammatory and anti-atherogenic agents," Diabetes/Metabolism Research and Reviews, vol. 24, no. 1, pp. 14-26, 2008.

[136] S. M. Haffner, A. S. Greenberg, W. M. Weston, H. Chen, K. Williams, and M. I. Freed, "Effect of rosiglitazone treatment on nontraditional markers of cardiovascular disease in patients with type 2 diabetes mellitus," Circulation, vol. 106, no. 6, pp. 679-684, 2002.

[137] G. Anfossi, I. Russo, and M. Trovati, "Platelet resistance to the anti-aggregating agents in the insulin resistant states," Current Diabetes Reviews, vol. 2, no. 4, pp. 409-430, 2006.

[138] J. D. McGarry, "Banting lecture 2001: dysregulation of fatty acid metabolism in the etiology of type 2 diabetes," Diabetes, vol. 51, no. 1, pp. 7-18, 2002.

[139] S. N. Leroyer, J. Tordjman, G. Chauvet, et al., "Rosiglitazone controls fatty acid cycling in human adipose tissue by means of glyceroneogenesis and glycerol phosphorylation," Journal of Biological Chemistry, vol. 281, no. 19, pp. 13141-13149, 2006.

[140] E. E. Kershaw, M. Schupp, H.-P. Guan, N. P. Gardner, M. A. Lazar, and J. S. Flier, "PPAR $\gamma$ regulates adipose triglyceride lipase in adipocytes in vitro and in vivo," American Journal of Physiology, vol. 293, no. 6, pp. E1736-E1745, 2007. 
[141] I. F. Charo, "Macrophage polarization and insulin resistance: PPAR $y$ in control," Cell Metabolism, vol. 6, no. 2, pp. 96-98, 2007.

[142] M. Bajaj, S. Suraamornkul, T. Pratipanawatr, et al., "Pioglitazone reduces hepatic fat content and augments splanchnic glucose uptake in patients with type 2 diabetes," Diabetes, vol. 52, no. 6, pp. 1364-1370, 2003.

[143] Y. Miyazaki, A. Mahankali, M. Matsuda, et al., "Effect of pioglitazone on abdominal fat distribution and insulin sensitivity in type 2 diabetic patients," The Journal of Clinical Endocrinology \& Metabolism, vol. 87, no. 6, pp. 2784-2791, 2002.

[144] A. B. Mayerson, R. S. Hundal, S. Dufour, et al., "The effects of rosiglitazone on insulin sensitivity, lipolysis, and hepatic and skeletal muscle triglyceride content in patients with type 2 diabetes," Diabetes, vol. 51, no. 3, pp. 797-802, 2002.

[145] M. Tiikkainen, A.-M. Häkkinen, E. Korsheninnikova, T. Nyman, S. Mäkimattila, and H. Yki-Järvinen, "Effects of rosiglitazone and metformin on liver fat content, hepatic insulin resistance, insulin clearance, and gene expression in adipose tissue in patients with type 2 diabetes," Diabetes, vol. 53, no. 8, pp. 2169-2176, 2004.

[146] L. L. Lipscombe, T. Gomes, L. E. Lévesque, J. E. Hux, D. N. Juurlink, and D. A. Alter, "Thiazolidinediones and cardiovascular outcomes in older patients with diabetes," Journal of the American Medical Association, vol. 298, no. 22, pp. 2634-2643, 2007.

[147] S. E. Nissen and K. Wolski, "Effect of rosiglitazone on the risk of myocardial infarction and death from cardiovascular causes," The New England Journal of Medicine, vol. 356, no. 24, pp. 2457-2471, 2007.

[148] M. Bajaj, S. Suraamornkul, L. J. Hardies, L. Glass, N. Musi, and R. A. DeFronzo, "Effects of peroxisome proliferatoractivated receptor (PPAR) $-\alpha$ and PPAR- $\gamma$ agonists on glucose and lipid metabolism in patients with type 2 diabetes mellitus," Diabetologia, vol. 50, no. 8, pp. 1723-1731, 2007.

[149] S. H. Han, M. J. Quon, and K. K. Koh, "Beneficial vascular and metabolic effects of peroxisome proliferator-activated receptor- $\alpha$ activators," Hypertension, vol. 46, no. 5, pp. 10861092, 2005. 


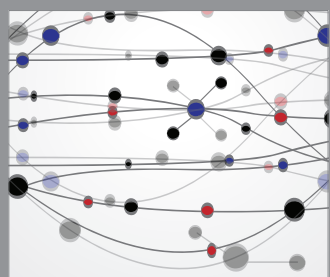

The Scientific World Journal
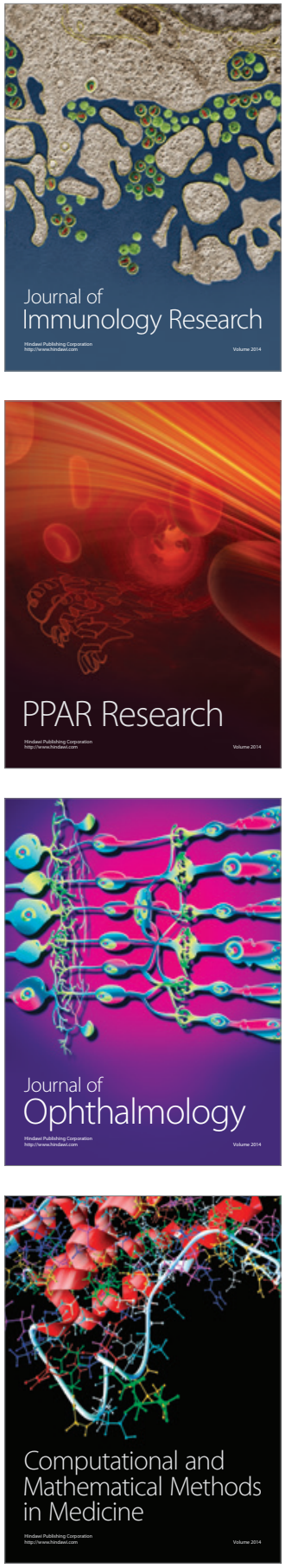

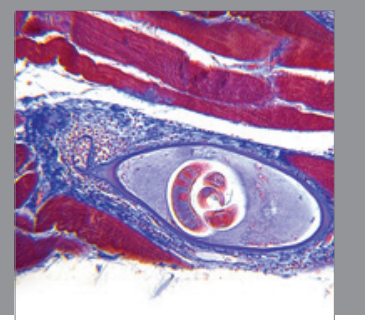

Gastroenterology

Research and Practice
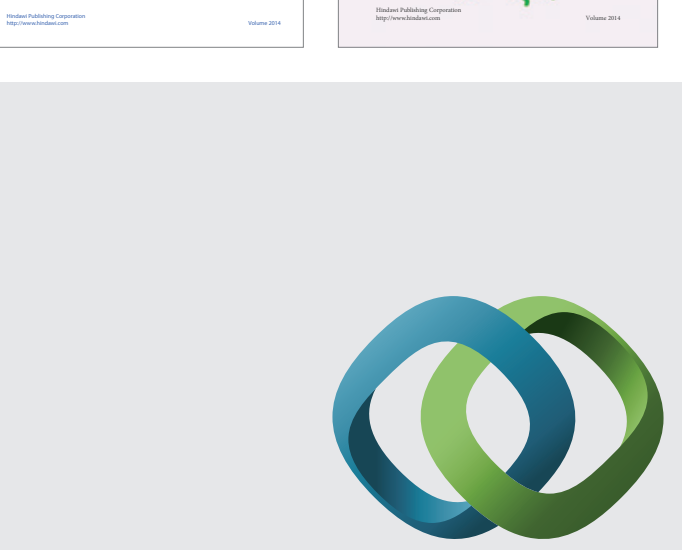

\section{Hindawi}

Submit your manuscripts at

http://www.hindawi.com
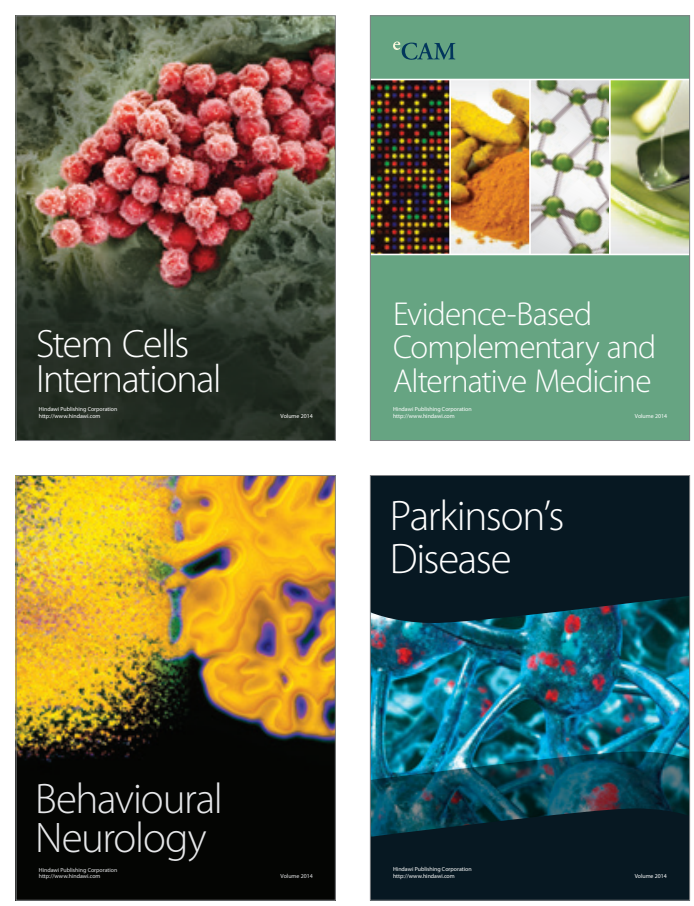

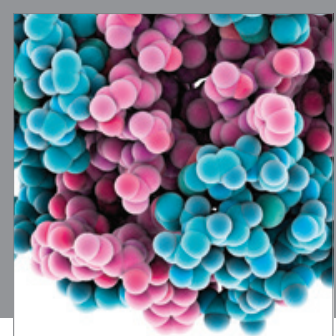

Journal of
Diabetes Research

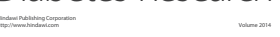

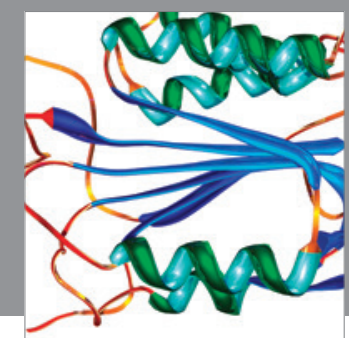

Disease Markers
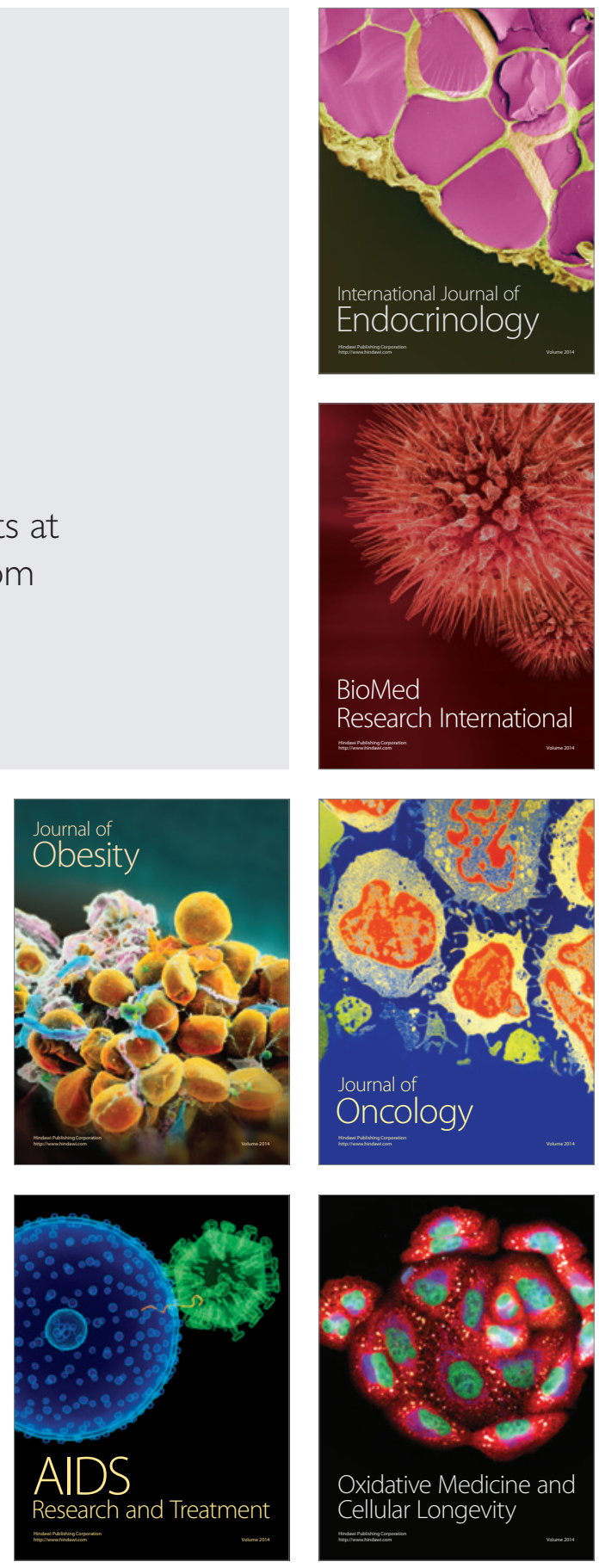